\title{
Research on the Differential Mechanisms of Knowledge Cross-Border Searching on Firms' Dual Innovation in the Digital Context: Based on Simulation of System Dynamics Model
}

\author{
Zhou Huiping $(\mathbb{D}$ and Yang Yuxin \\ School of Business Administration, Guangdong University of Finance and Economics, Guangzhou 510320, China \\ Correspondence should be addressed to Zhou Huiping; zhouhuiping0807@163.com
}

Received 23 April 2021; Revised 25 August 2021; Accepted 28 August 2021; Published 13 September 2021

Academic Editor: Alicia Cordero

Copyright (C) 2021 Zhou Huiping and Yang Yuxin. This is an open access article distributed under the Creative Commons Attribution License, which permits unrestricted use, distribution, and reproduction in any medium, provided the original work is properly cited.

\begin{abstract}
Acquiring and combining heterogeneous knowledge resources across organizational boundaries are an important path for the success of enterprises' innovation. From the perspective of the relation attributes between knowledge elements, this paper divides knowledge cross-border searching into two types: domain knowledge searching and architectural knowledge coupling searching. Then, we construct a system dynamics model and use Vensim PLE software to carry out simulation analysis to explore the differential mechanisms of knowledge cross-border searching influence firms' dual innovation in the context of digital transformation. The analysis results show that domain knowledge searching positively affects firms' iterative innovation, while there is an inverted U-shaped relationship between architectural knowledge searching and firms' disruptive innovation, indicating that different types of knowledge cross-border searching have differential effects on firms' dual innovation. The simulation results also address that digital resources can promote enterprises' dual innovation in the process of knowledge cross-border searching. The research results reveal that the internal laws of knowledge cross-border searching affect enterprises' dual innovation in the context of digital transformation and provide a theoretical reference for enterprises to effectively use digital technology to adopt knowledge searching activities.
\end{abstract}

\section{Introduction}

In the era of digital economy, firms actively combine a large amount of heterogeneous knowledge resources from their partners to achieve their innovation goals [1-3]. For example, Huawei builds a global R\&D network to extensively search for knowledge elements to realize new technology creation. Internet companies such as Xiaomi and Tencent solicit customer opinions and adopt the innovative modes of 'imitating one generation, developing one, and preresearching one generation' to achieve great success. How can firms search for and combine different types of knowledge to achieve innovation? This is an important topic for firms to build sustainable competitive advantages in the context of digitization.

Organizational innovation is essentially a process of continuous knowledge combination $[2,4]$. Iterative innovation and disruptive innovation have constituted important dual innovation modes for firms to achieve innovation outcomes under the digital background. Driven by digital technologies such as big data and the Internet of Things, the digital firms, digital markets, digital users, and governments have formed a digital ecosystem of resource interaction and sharing by online and offline way [5]. The digital ecosystem has broken down the limitations of organizational boundaries and technological distance and provided a large number of opportunities for firms to search for heterogeneous knowledge elements to achieve innovation success.

Knowledge cross-border searching is the process of companies searching and combining knowledge elements across organizational boundaries and knowledge bases [6]. Previous studies have focused on the characteristics of knowledge searching and the mechanisms that affect 
enterprises' innovation from static perspectives such as distance, method, content, and time [3, 7]. Generally speaking, the existing literature mainly emphasizes the role of acquisition and possession of heterogeneous knowledge in the growth of enterprises and the construction of core competitiveness, which cannot meet the dynamic strategy of quickly identifying and repeatedly editing knowledge elements required for innovation from the massive knowledge sources in digital age [3, 7]. Whether organizations searching for different types knowledge elements have differential impacts on firms' disruptive innovation and iterative innovation in the context of digital transformation? How can organizations effectively use various resources to achieve innovation success? System dynamics is a methodology for understanding the dynamic behavior of a complex system that are characterized by accumulations, feedback loops, time delays, and nonlinearity [8]. Thereby, this paper uses system dynamics models and simulation analysis methods to explore the differential mechanisms of knowledge cross-border searching on enterprises' disruptive innovation and iterative innovation in the context of digitalization, to reveal the internal laws of knowledge searching affecting organizational innovation and provide a reference for enterprises to make full use of knowledge resources from ecological partners.

\section{The Dynamic Process of Knowledge Cross- Border Searching in Digital Context}

2.1. The Structure of Knowledge Cross-Border Searching. Firms' innovation is essentially a process of continuous knowledge combination. In the digital ecosystem, firms build collaborative relationships through customers, partners, competitors, intermediaries, etc., to extensively search for heterogeneous knowledge elements to achieve their innovation goals. Existing knowledge search literature mainly divides the dimensions of knowledge cross-border searching from perspectives of distance, method, content, time, etc., to describe the main characteristics of knowledge searching and explore the specific mechanisms of knowledge searching affects enterprises' innovation [6, 7]. Previous studies mainly emphasized the possession of knowledge resources to promote innovation, and few researches have distinguished the attributes of different types of knowledge elements and its differential impacts on organizational innovation [3]. This is not conducive for companies to manage knowledge searching strategies based on the types of knowledge elements they need. In the digital ecosystem, organizations are faced with massive differentiated, reeditable, and recyclable knowledge resources. In this context, firms' knowledge cross-border searching process should be guided by organization strategy, and they must quickly identify and combine specific knowledge required for innovation from massive knowledge resources.

A firm's knowledge base is a collection of knowledge elements that have specific structural relationships with each other. Combining knowledge elements in different fields and categories is crucial to the success of enterprise innovation [9]. Knowledge elements are highly malleable. Thus, different knowledge elements can be recombined in a variety of ways to create new inventions [10]. What is more, the relational structure between knowledge elements formed by the reorganization of prior knowledge constitutes the source of value creation [10]. On this basis, Yayavaram et al. [9] classified knowledge sources from the relational structure of knowledge elements and proposed two types of knowledge structure in innovation searching process: (1) domain knowledge, knowledge elements possessed by different technical fields; (2) architectural knowledge, knowledge on how to combine elements of knowledge in different technical fields. At the same time, domain knowledge and architectural knowledge from partners can promote the success of innovation by deepening or expanding organizational knowledge base [9]. This classification of knowledge sources provides a unique and novel perspective for knowledge cross-border searching in the digital context. Based on the above, this paper defines two types of knowledge crossborder searching from the relational structure of knowledge elements, domain knowledge searching and architectural knowledge searching, to explore the dynamic path of knowledge cross-border searching affects enterprises' innovation in the context of digital transformation.

2.1.1. Domain Knowledge Searching. Domain knowledge refers to the knowledge elements possessed by enterprises in different technical fields, which are mainly used to describe cognitive objects or their constituent elements [9]. With reference to the prior literature, this paper defines domain knowledge searching as a company search for knowledge elements that can reflect the core design concepts and specific functions of products from ecological partners, including specialized resources, technologies, and capabilities related to organizational characteristics.

\subsubsection{Architectural Knowledge Searching. Architectural} knowledge refers to the knowledge that an enterprise possesses on how to combine knowledge elements in different technical fields, which is mainly used to describe the relationship between different cognitive objects and their constituent elements [9]. We define architectural knowledge searching as a company search for knowledge elements about the overall structure or process that involves sharing, learning, and creating within the organization from ecological partners, including communication channels, information filters, and problem-solving strategies.

\subsection{Influencing Factors of Knowledge Cross-Border Searching in Digital Context}

2.2.1. Management Resources. Management resources include knowledge or information related to a firm's internal culture, system, and norms. The reasonable application of management resources will help promote the reorganization of external resource elements and achieve knowledge valueadded and innovation capabilities through the effective interaction of internal and external resources. 
2.2.2. Digital Resources. Digital resources refer to various digital resources for organizations to conduct extensive knowledge searching and value creation activities, including emerging digital technologies such as big data, Internet of Things, and cloud computing. Digital resources can help improve the efficiency and effectiveness of knowledge searching, thus increasing the output of innovation.

2.2.3. Digital Strategic Capabilities. Digital strategic capability refers to the comprehensive ability to apply emerging digital technologies to promote resource integration and innovation value-added. Digital strategy capabilities reflect the organization's forward-looking control and foresight in digital technology [10]. Thus, digital strategy capabilities can enhance the dynamic ability of firms to respond to complex environment.

2.2.4. Digital Dynamic Capabilities. Digital dynamic capability is defined as the ability of firms to adopt digital technology to identify, integrate, and reorganize internal and external resources to respond flexibly and quickly to various changes in market demands [11]. In the context of digitization, organizations' external environment is full of ambiguities and uncertainties [12]. Therefore, companies need to identify and quickly respond to changes in ecological partners and external environment during knowledge searching process to reduce costs and risks.

2.2.5. Digital Entrepreneurship. Digital entrepreneurship is the ability of enterprises to gain insight into the digital situation, to identify digital opportunities and capture digital strategic resources, in order to organize digital resource coupling activities in the process of digitization [13, 14]. In the digital ecosystem, only continuous actions to improve capabilities can promote organizations to adjust and allocate resource structure and knowledge matching methods in a timely manner, and to take advantage of the trend to continuously create new knowledge to sustain long-term competitive advantages.

2.2.6. Organizational Inertia. Organizational inertia is the 'crisis' caused by path dependence, and it is a rigidity that enterprises cannot flexibly change original resources and organizational model. When companies use digital resources to carry out knowledge searching activities, organizational inertia makes them unable to have insight into the dynamic trends of internal and external environments in a timely manner, and they are prone to endogenous dependence and capacity rigidity.

\section{The Differentiated Mechanism of Knowledge Cross-Border Searching Affects Firms' Dual Innovation in Digital Context}

In the digital ecosystem, the process of heterogeneous knowledge searching is bound to be accompanied by the accumulation and application of innovative knowledge.
Enterprises build a digital ecosystem with high degrees of knowledge flow and interaction through collaborative and cooperative relationships, to arrange and combine heterogeneous knowledge resources in this ecosystem, which can help achieve the accumulation and redundancy of knowledge resources within the organization to help solve problems and technical difficulties or bottlenecks to achieve innovation success. At the same time, the contextual factors such as digital resources and digital dynamic capabilities will promote the realization of this process. Based on the influencing factors of knowledge cross-border searching mentioned above, the conceptual model of knowledge crossborder searching affects the firms' dual innovation proposed (as seen in Figure 1).

\subsection{System Dynamics Model of Knowledge Cross-Border} Searching Influences Firms' Dual Innovation in Digital Context. System dynamics is used to understand the dynamic processes that lead to different performance trajectories of various firms over time, which can enhance explanatory power on how managerial decision making influences firm dynamics and thus heterogeneity in performance [15-17]. Based on the above conceptual model, we can infer that there are multiple dynamic feedback paths along with the dynamic accumulation of knowledge resources in this system. Therefore, this paper constructs a system dynamics model to study the realization mechanism of knowledge cross-border searching on enterprises' dual innovation driven by digitization.

3.2. The Causality and Feedback Loops. There are six forward loops that can repeat cycles as follows:

(1) Digitization $\uparrow \longrightarrow$ digital strategic capabilities $\uparrow$ $\longrightarrow$ digital entrepreneurship $\uparrow \longrightarrow$ disruptive innovation $\uparrow \longrightarrow$ stock of innovation results $\uparrow$ $\longrightarrow$ digitization $\uparrow$. In the process of digital transformation, with the use of digital resources such as big data, Internet of Things, and cloud computing, firms will inevitably enhance their digital strategic ability to effectively use digital technology and drive them to make continuous changes and technological breakthroughs, to achieve disruptive technology and products breakthrough, thereby enhancing their innovation results. At the same time, through the process of transformation and application of innovation achievements, firms can enhance economic and technical strengths and promote them to carry out digital transformation strategy further.

(2) Digitization $\uparrow \longrightarrow$ digital strategic capabilities $\uparrow$ $\longrightarrow$ digital entrepreneurship $\uparrow \quad$ iterative innovation $\uparrow \longrightarrow$ stock of innovation results $\uparrow \longrightarrow$ digitization $\uparrow$. When firms put forward digital transformation, the promotion of digital resources will inevitably enhance their digital strategic ability to effectively satisfy the use of customers and markets and drive them to make continuous technological upgrade, to achieve technology improvement and 


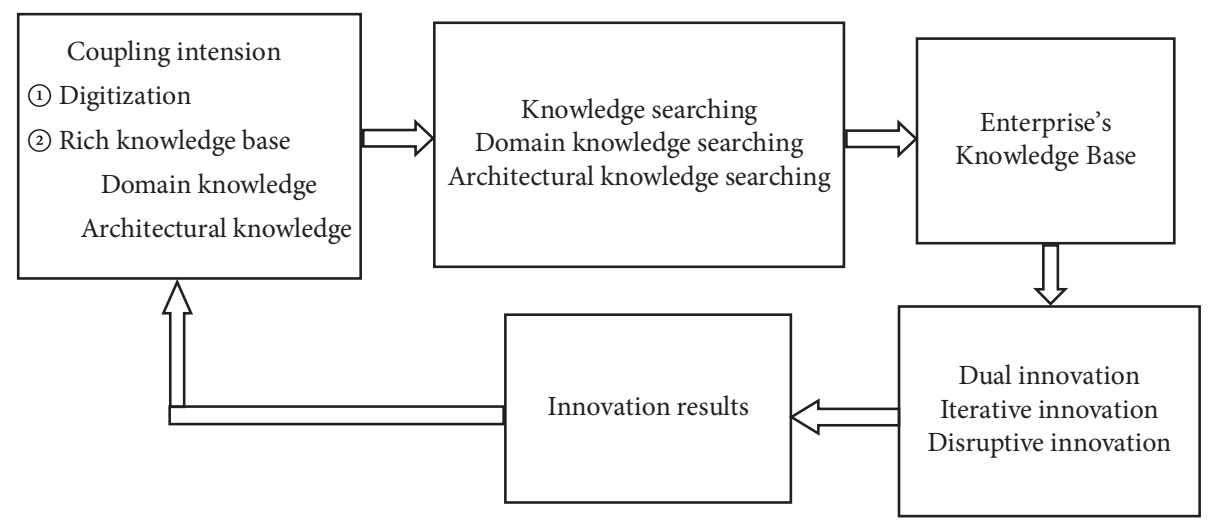

Figure 1: The conceptual model.

innovation, thereby enhancing their innovation results. In the meantime, the increase of innovation achievements can push firms to carry out digital transformation strategy further.

(3) Digitization $\uparrow \longrightarrow$ digital strategic capabilities $\uparrow$ $\longrightarrow$ digital dynamic capabilities $\uparrow \longrightarrow$ digital entrepreneurship $\uparrow \longrightarrow$ disruptive innovation $\uparrow$ $\longrightarrow$ stock of innovation results $\uparrow \longrightarrow$ digitization $\uparrow$.

In the process of digital transformation, the introduction of digital resources will improve firms' digital strategic ability and then promote their dynamic ability to adapt to the changes of the external environment, in order to seize the opportunity to achieve disruptive technology and products breakthrough, thereby enhancing their disruptive innovation results. At the same time, through the process of transformation and application of innovation achievements, firms can enhance their ability to carry out digital transformation strategy further.

(4) Digitization $\uparrow \longrightarrow$ digital strategic capabilities $\uparrow$ $\longrightarrow$ digital dynamic capabilities $\uparrow \longrightarrow$ digital entrepreneurship $\uparrow \longrightarrow$ iterative innovation $\uparrow$ $\longrightarrow$ stock of innovation results $\uparrow \longrightarrow$ digitization $\uparrow$.

Similarly, in the process of digital transformation, the adoption of digital resources will improve firms' digital strategic ability and then promote their dynamic ability to adapt to the changes of the external environment, in order to seize the opportunity to upgrade their technology to satisfy customers' demands, thereby enhancing their iterative innovation results. At the same time, through the process of transformation and application of innovation achievements, firms can enhance their ability to carry out digital transformation strategy further.

(5) Domain knowledge searching $\uparrow \longrightarrow$ iterative innovation $\uparrow \longrightarrow$ stock of innovation results $\uparrow$ $\longrightarrow$ innovation performance $\uparrow \longrightarrow$ domain knowledge searching $\uparrow$.

In the process of extensively searching for core resources and technology, enterprises have increased the speed and effect of improving the performance of original products and increased the efficiency of the transformation of innovation results. At the same time, the improvement of innovation results will promote organizations adopting domain knowledge searching strategy to continuously create sustainable competitive advantages. Thus, a complete positive feedback loop is formed.

(6) Architectural knowledge searching $\uparrow \longrightarrow$ disruptive innovation $\uparrow \longrightarrow$ stock of innovation results $\uparrow$ $\longrightarrow$ innovation performance $\uparrow \longrightarrow$ architectural knowledge searching $\uparrow$.

In the process of extensively searching for architectural knowledge related to internal communication channels and problem-solving strategies, organizations will form the ability to actively seek changes to promote the accumulation of knowledge resources and help them create more novel technologies or products to achieve innovative results and value-added. In the meantime, the value-added innovation results will encourage enterprises to invest more resources in developing architectural knowledge searching strategies to consolidate their competitive advantages. Therefore, a positive feedback loop is formed.

Based on the above analysis of the causal feedback loops, as well as the theoretical model of the impacts of knowledge cross-border searching on firms' dual innovation, the causal relationship model is proposed (as shown in Figure 2), which can reflect the qualitative influencing relationship between variables in this system.

3.3. Hypothesis. In order to construct the system dynamics model that knowledge cross-border searching affects firms' dual innovation, we thus propose the following hypothesis:

In the process of digital transformation, with the use of digital resources such as big data, Internet of Things, and cloud computing, firms will inevitably enhance their digital strategic ability to make foresight use of digital technology to deal with the dynamic changes in environment, to develop breakthrough technology and iterative products $[11,12]$, thereby enhancing their innovation results. Therefore, we can propose that: 


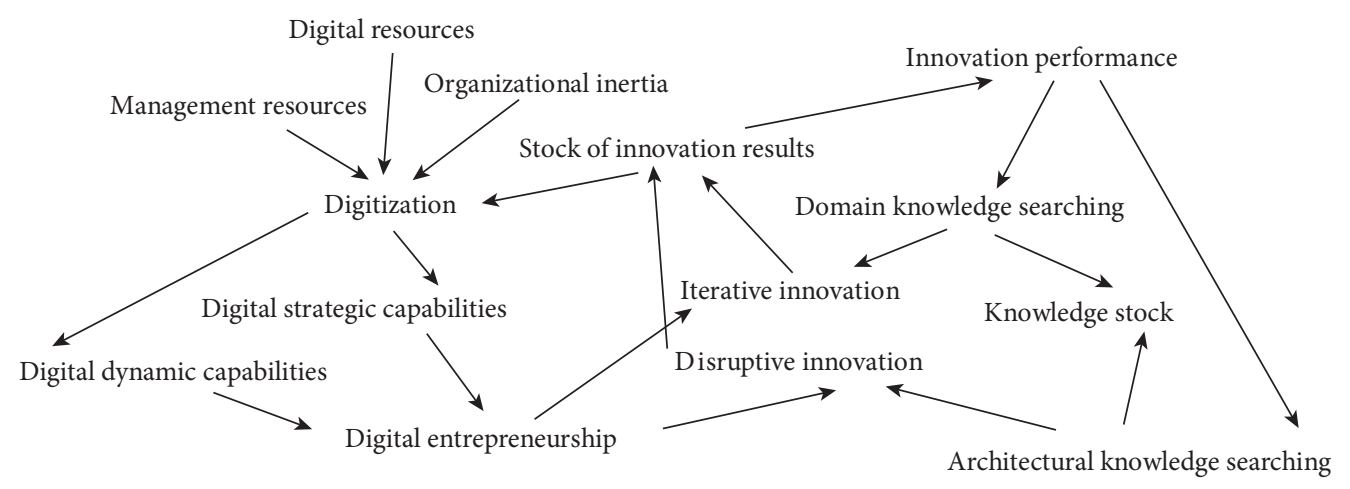

Figure 2: The causal loops model.

H1. The adoption of digital resources for digital transformation will promote the improvement of digital strategic capabilities, digital dynamic capabilities, and digital entrepreneurship, thus further promoting the improvement of innovation results through two types of innovation strategies: iterative innovation and disruptive innovation.

The combination of domain knowledge can help firms broaden their existing knowledge base [9]. Therefore, domain knowledge searching is more conducive to achieve the integration and reorganization of old and new knowledge, thus increasing firms' ability to update their technology and products to meet market demands.

Although the integration of architectural knowledge can help firms update their internal practices and processes [9], however, when organizations search for a large amount of architectural knowledge about problem-solving strategies and product process, they will disperse resources to integrate core products or technologies and cause big cost for firms technology improvement activities. Thus, we can propose that:

$\mathrm{H} 2$. The domain knowledge searching can promote the increase of iterative innovation.

The integration of architectural knowledge is conducive to the realization of new ways or ideas and promotes the development of breakthrough knowledge [13]. Therefore, when enterprises search for architectural knowledge about communication channels, information filtering, and problem solving from, it will stimulate the effective combination of internal and external knowledge and create new knowledge for their disruptive activities.

On the contrary, the combination of domain knowledge will restrict enterprises to the iteration process of existing technology and product, and it is not conducive to the generation of new inventions [18]. Thereby, when firms search for too much domain knowledge, it will increase the overlap of internal and external knowledge and hinder the flexibility of knowledge absorption and reorganization, thereby weakening the ability of enterprises to develop disruptive technologies. It can reasonably hypothesize that:
H3. The architectural knowledge searching can promote the increase of disruptive innovation.

Thus, the system dynamics model is shown in Figure 3. This model contains two state variables (S), six rate variables $(R)$, seven auxiliary variables $(A)$, and seven constants $(\mathrm{C})$, which can reflect the relationships between stock and flow in the dynamic feedback process.

3.4. Equations Design. According to the system dynamics model, the setting of relevant variables in this paper is shown in the following equations:

\subsubsection{The Equations Design and Explanations of State Variables}

L1 Knowledge stock= INTEG (Domain knowledge searching + Architectural knowledge searching-Knowledge loss, 30)

L2 Stock of innovation results = INTEG (Disruptive innovation + Iterative innovation-Innovation results loss, 10)

The initial of knowledge stock and innovation results is 30 and 10 , respectively.

\subsubsection{The Equations Design and Explanations of Rate Variables}

R1: Domain knowledge searching=DELAY1I ((Domain knowledge searching capability*innovation performance), 3, 0).

Domain knowledge searching has a lag, so the firstorder demonstration function is used to represent the knowledge searching process. The lag time is 3 months, the loss rate is set as $5 \%$, and the initial value of domain knowledge searching is 0 .

R2: Architectural knowledge searching = DELAY1I ((Architectural knowledge searching capability*innovation performance), 3, 0).

Architectural knowledge searching has a lag, so the first-order demonstration function is used to represent the knowledge searching process. The lag time is 3 


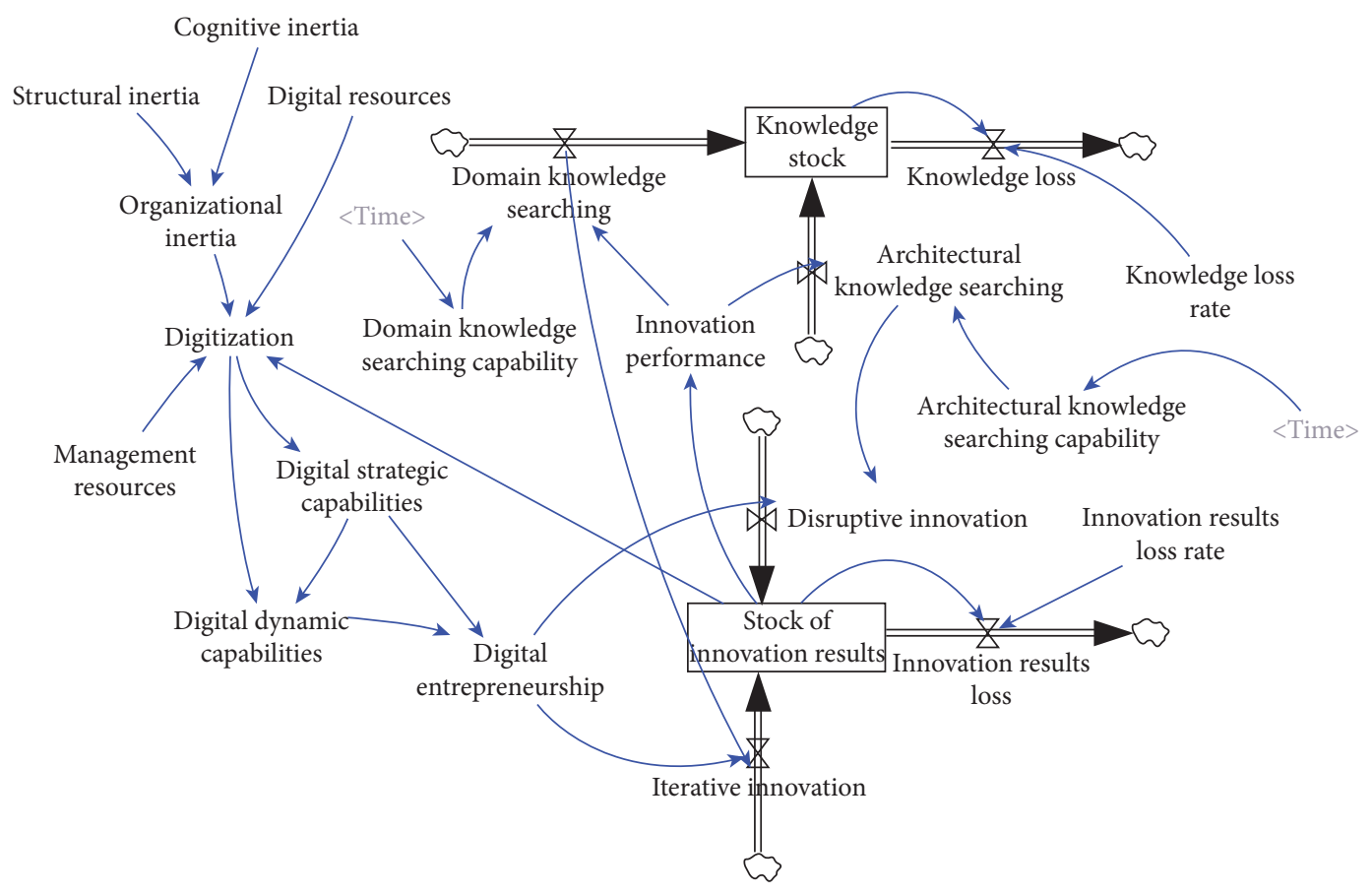

Figure 3: The system dynamics model.

months, the loss rate is set as 5\%, and the initial value of architectural knowledge searching is 0 .

R3: Knowledge loss=DELAY1I (knowledge stock*knowledge loss rate, 6, 0)

Knowledge loss has a lag, so the first-order demonstration function is used to represent the knowledge loss process. The lag time is 6 months, the loss rate is set as $2 \%$, and the initial value of knowledge loss is 0 .

R4: Disruptive innovation = DELAY1I (Architectural knowledge searching* Digital entrepreneurship, 6, 0)

Disruptive innovation has a lag, so the first-order demonstration function is used to represent the disruptive innovation process. The lag time is 6 months, and the initial value of disruptive innovation is 0 .

R5: Iterative Innovation = DELAY1I (Domain knowledge Searching*Digital Entrepreneurship, 6, 0).

Iterative innovation has a lag, so the first-order demonstration function is used to represent the iterative innovation process. The lag time is 6 months, and the initial value of iterative innovation is 0 .

R6: Innovation results loss = DELAY1I (Stock of innovation results*innovation results rate, 9,0$)$.

Innovation results loss has a lag, so the first-order demonstration function is used to represent the innovation results process. The lag time is 6 months, the loss rate is set as $5 \%$, and the initial value of innovation results loss is 0 .

3.4.3. The Equations Design and Explanations of Auxiliary Variables. S1: Digitization $=$ Stock of innovation results $0.1 *$ management resources $0.3^{*}$ digital resources $0.3^{*}$ organizational inertia0.3.

S2: Digital Entrepreneurship = Digital dynamic capability + digital strategic capability.

S3: Digital strategic capability $=$ Digitization ${ }^{*} 0.5$.

S4: Digital dynamic capability $=$ Digitization $^{*} 0.5+$ Digital strategic capability* 0.5 .

S5: Domain knowledge searching capability $=$ WITH LOOKUP (Time, $([(0,0)-(36,1)],(0,0.2),(36,0.35)))$. The domain knowledge searching capability is represented by a table function. Within 36 months of the simulation time, the domain knowledge searching capability increases from 0.2 to 0.35 at the linear law.

S6: Architectural knowledge searching capability = WITH LOOKUP $([(0,0)-(36,1)],(0,0.2),(18,0.5),(36$, $0.35))$.

The architectural knowledge searching capability is represented by the table function. Within 36 months of the simulation time, the architectural knowledge searching capability increases from 0.2 to 0.35 at the nonlinear law.

S7: Organizational inertia $=$ Structural inertia-cognitive inertia.

S8: Innovation performance $=$ Stock of innovation results*0.1.

\subsubsection{The Equations Design and Explanations of Constant.}

$\mathrm{C} 1$ : management resources, C2 digital resources, C3 

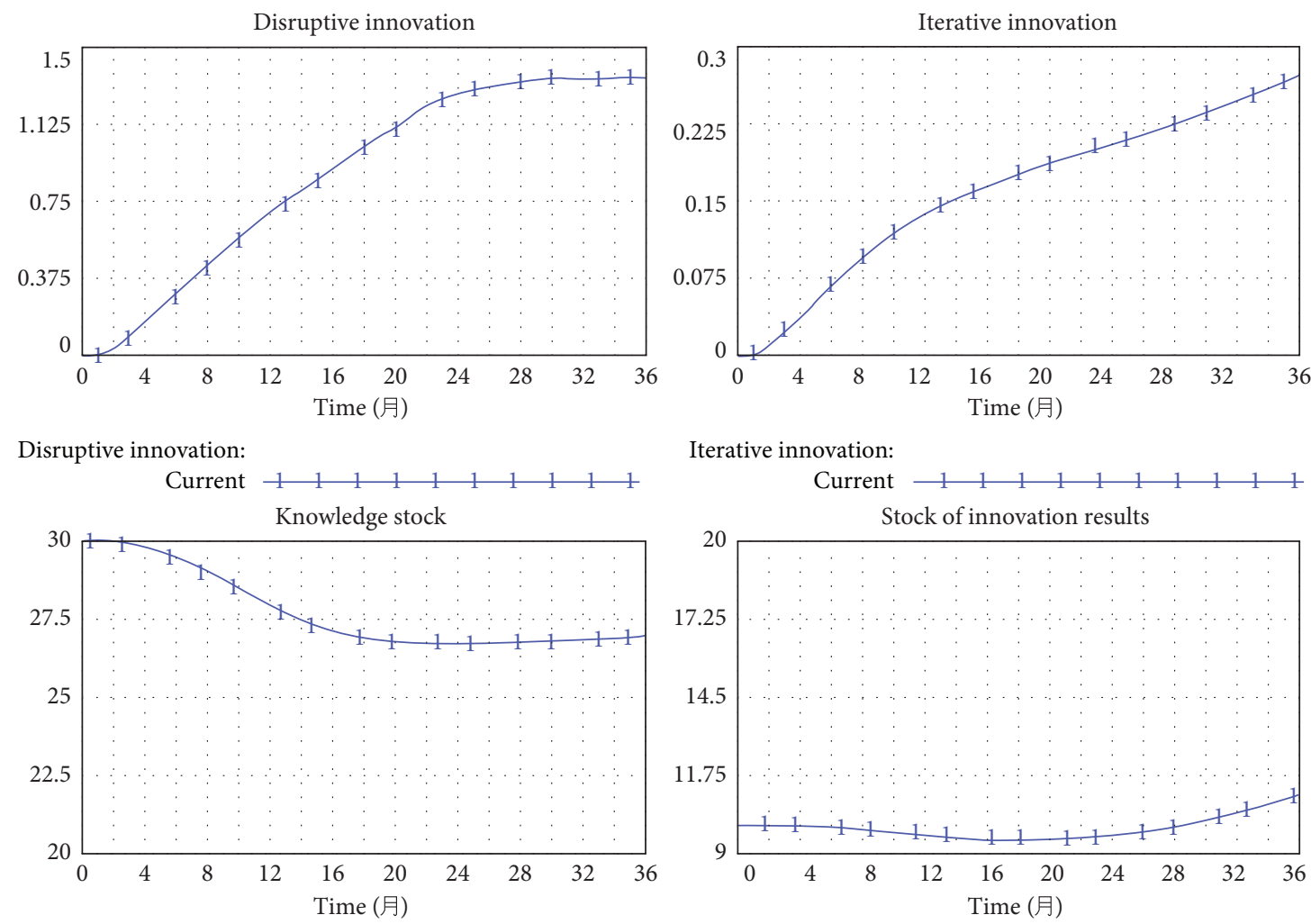

$\begin{array}{rlllllllllll}\text { Current } & 1 & 1 & 1 & 1 & 1 & 1 & 1 & 1 & 1 & 1\end{array}$

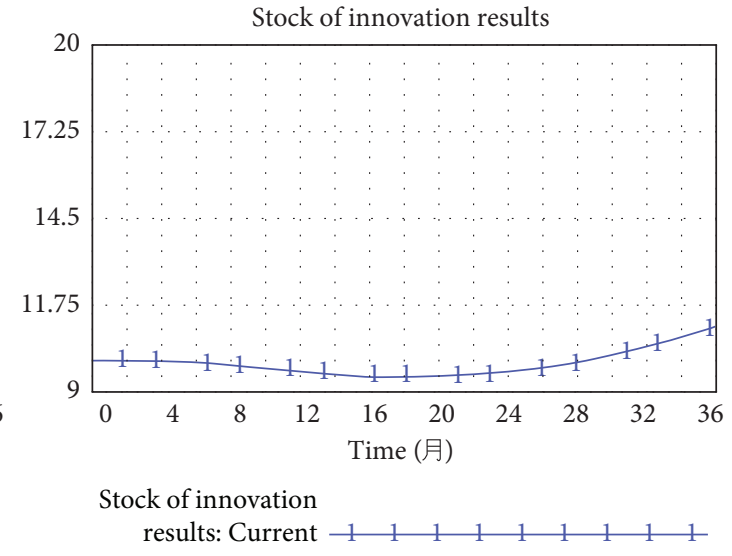

FIGURE 4: Simulation results of system dynamics.

digital dynamic capabilities, $\mathrm{C} 4$ structural inertia and C5 cognitive inertia are changes within $[0,1]$

Management resources $=$ RANDOM NORMAL $(0,1$, $0.4,0.01,0.3$ )

Digital resources $=$ RANDOM NORMAL $(0,1,0.3$, $0.01,0.2)$

Structural inertia $=$ RANDOM NORMAL $(0,1,0.6$, $0.01,0.5)$

Cognitive inertia $=$ RANDOM NORMAL $(0,1,0.4$, $0.01,0.3)$

C5: Innovation results loss $=0.05$

C6: Knowledge loss $=0.05$

\section{Simulation and Sensitivity Analysis}

4.1. Simulation. This paper adopts Vensim PLE software to simulate the system dynamics model to verify its effectiveness and analyze its sensitivity. Set the initial value of management resources as 0.4 , the initial value of digital resources is 0.3 , the initial value of structural inertia is 0.6 , the initial value of cognitive inertia is 0.4 , and the initial value of digital dynamic capabilities is 0.5 . The simulation parameters are set as follows: initial time $=0$, end time $=36$, time step $=1$, time unit $=$ month.

The simulation results (as seen in Figure 4) show that, firstly, iterative innovation has a stable growth; the growth of disruptive innovation shows an inverted U-shaped curve that first increases and then decreases, in the 28 month or so, and the marginal increment of disruptive innovation approaches 0 . Secondly, knowledge stock shows a U-shaped curve growth that first decreases and then increases. After about 18 months of the simulation time, the amount of growth gradually increased. Thirdly, the stock of innovation results shows a curvilinear growth, and the marginal growth is generally increasing. The above simulation results are consistent with the actual situation of enterprises' knowledge searching, which indicates that the simulation model of knowledge cross-border searching affects firms' dual innovation in this paper, has basic validity, and can further conduct a sensitivity analysis.

4.2. Sensitivity Analysis. The sensitivity analysis is to judge the sensitivity of the model by changing parameter values to observe the curve changes of variables. This paper adjusts the changes of three factors, namely, domain knowledge searching capability, architectural knowledge searching capability, and digital resources, to identify the role of knowledge cross-border searching in promoting enterprises to achieve dual innovation in digital context.

4.2.1. Sensitivity Analysis of Digital Resources. Keeping other parameters constant in the system, we increase the value of digital resources from 0.3 (CURRENT curve) to 0.4 (CURRENT 1 curve) and 0.5 (CURRENT 2 curve). The 

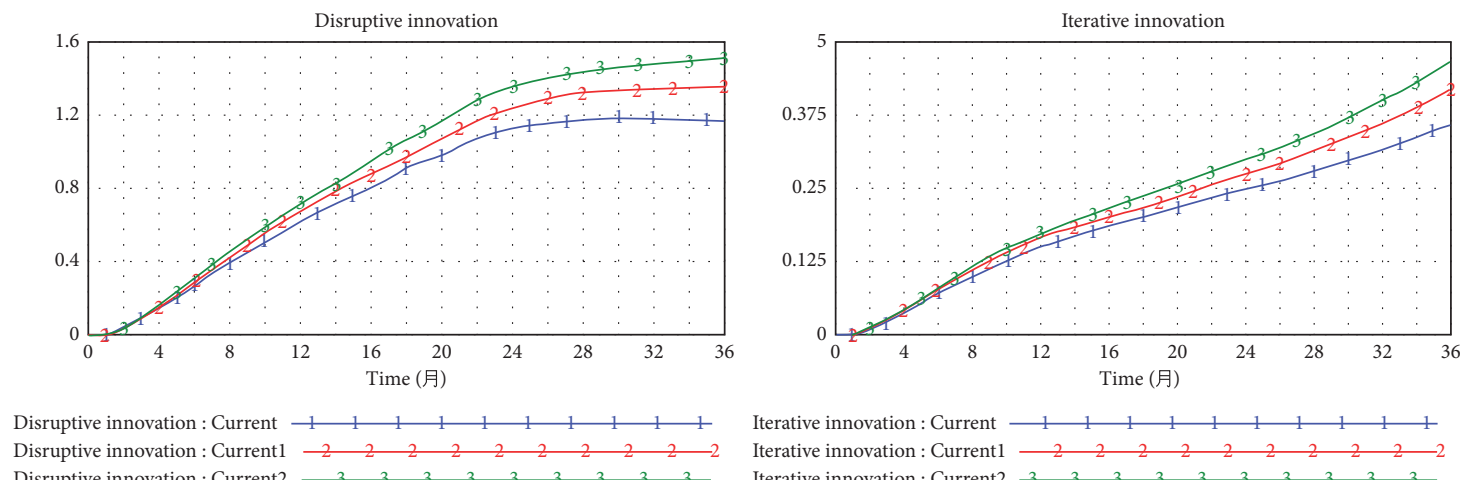

Disruptive innovation : Current

erative innovation : Current 2

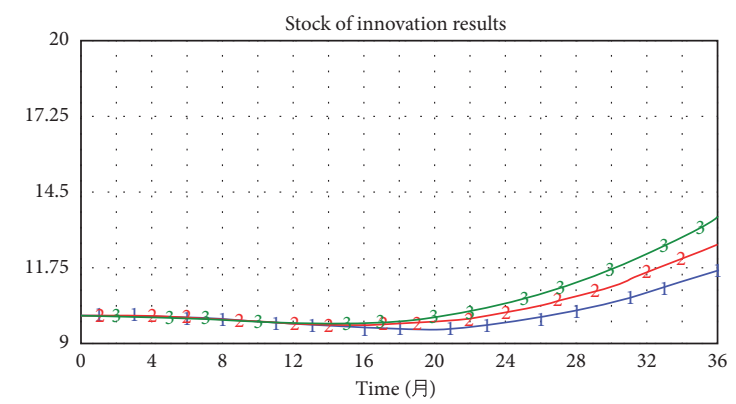

Stock of innovation results : Current $\begin{array}{llllllllllll}1 & 1 & 1 & 1 & 1 & 1 & 1 & 1 & 1 & 1\end{array}$

Stock of innovation results : Current1 \begin{tabular}{lllllllllll}
\hline & 2 & 2 & 2 & 2 & 2 & 2 & 2 & 2 & 2
\end{tabular}

Stock of innovation results : Current2

FIGURE 5: The impacts of digital resources on iterative innovation, disruptive innovation, and stock of innovation results.

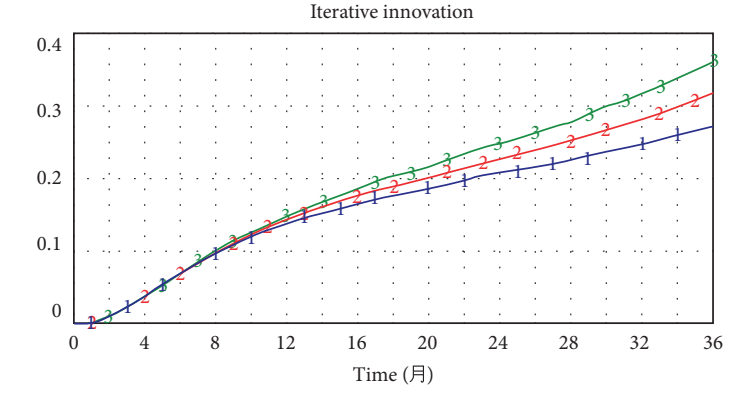

Iterative innovation : Current $\quad \begin{array}{llllllllllll}1 & 1 & 1 & 1 & 1 & 1 & 1 & 1 & 1 & 1\end{array}$ Iterative innovation : Current Iterative innovation : Current 2

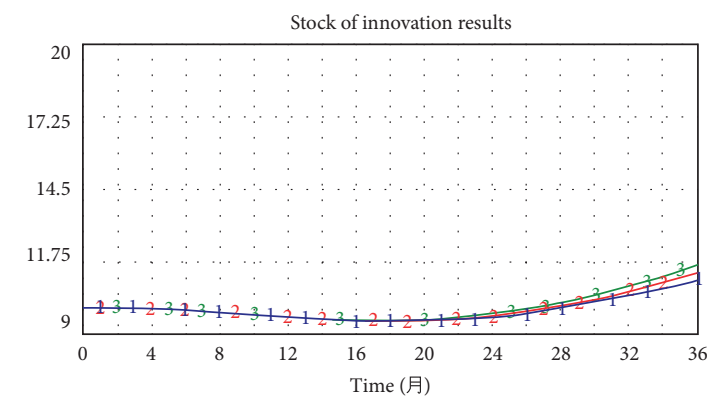

Stock of innovation results : Current $\begin{array}{llllllllllll}1 & 1 & 1 & 1 & 1 & 1 & 1 & 1 & 1\end{array}$ Stock of innovation results : Currentl $\begin{array}{llllllllllll}2 & 2 & 2 & 2 & 2 & 2 & 2 & 2 & 2 & 2 & 2\end{array}$ Stock of innovation results : Current2

FIGURE 6: The impacts of domain knowledge searching on iterative innovation and stock of innovation results.

changes of iterative innovation, disruptive innovation, and stock of innovation results are shown in Figure 5. It can be seen that, with the improvement of digital resources, iterative innovation, disruptive innovation, and stock of innovation results have gradually increased, indicating that digital resources can enhance firms' innovation activities and their innovation results.

4.2.2. Sensitivity Analysis of Domain Knowledge Searching Capability. Keeping other parameters constant in the system, we increase the growth value of domain knowledge searching capability from 0.15 (CURRENT curve) to 0.2 (CURRENT 1 curve) and 0.25 (CURRENT 2 curve). The changes of iterative innovation and stock of innovation results are shown in Figure 6. It can be seen that, with the improvement of domain knowledge searching capability, both iterative innovation and stock of innovation results have gradually increased, indicating that domain knowledge searching can promote iterative innovation and innovation results.

\subsubsection{Sensitivity Analysis of Architectural Knowledge} Searching Capability. Keeping other parameters constant in the system, we increase the growth value of architectural knowledge searching capability from 0.15 (CURRENT curve) to 0.2 (CURRENT 1 curve) and 0.25 (CURRENT 2 curve). The changes of disruptive innovation and stock of innovation results are shown in Figure 7. It can be seen that, in the early stage of simulation time, with the improvement of architectural knowledge searching capability, disruptive 


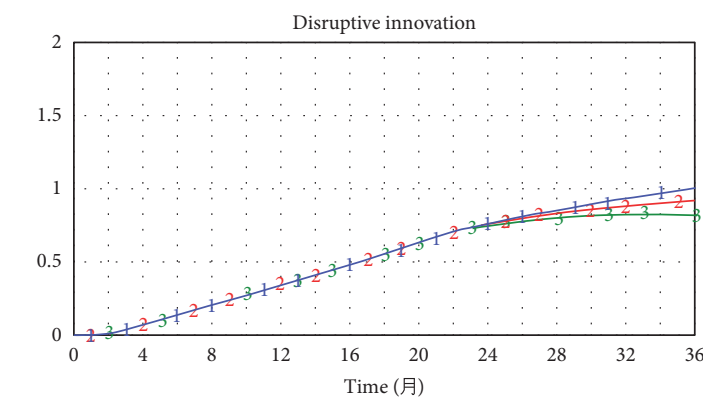

Disruptive innovation : Current

Disruptive innovation : Current1 \begin{tabular}{llllllllll}
\hline & 2 & 2 & 2 & 2 & 2 & 2 & 2 & 2 & 2
\end{tabular} Disruptive innovation : Current2

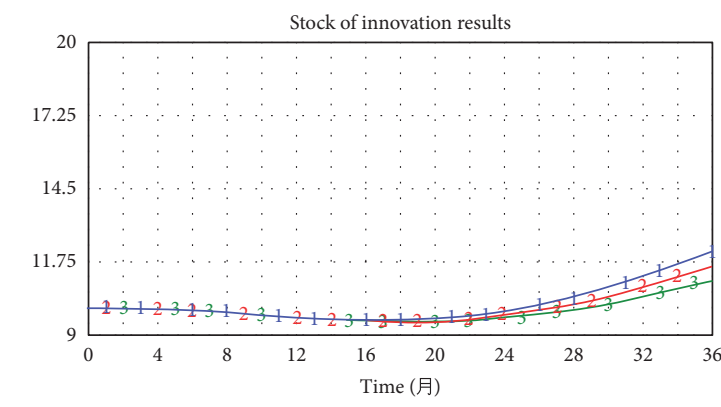

$\begin{array}{lllllllllllllll}\text { Stock of innovation results : Current } & 1 & & 1 & & 1 & 1 & 1 & 1 & 1 & 1 & 1 & 1 & 1\end{array}$ Stock of innovation results : Current2

FIgURE 7: The impacts of architectural knowledge searching on disruptive innovation and stock of innovation results.

innovation gradually increased, but in about 24 months later, with the increase architectural knowledge searching capability, the disruptive innovation is gradually decreased. It shows that there is an inverted U-shaped relationship between architectural knowledge searching and enterprises' disruptive innovation. Similarly, the simulation result shows that architectural knowledge searching can help promote innovation results.

\section{Conclusions and Implications}

This paper adopts system dynamics and simulation analysis by Vensim PLE software to identify the differentiated mechanisms of knowledge cross-border searching on enterprises' dual innovation in digital context. The analysis results show that domain knowledge searching has a positive impact on firms' iterative innovation; There is an inverted U-shaped relationship between architectural knowledge searching and enterprises' disruptive innovation; digital resources can improve organizations' dual innovation and innovation results.

The simulation results confirm the view that different types of knowledge cross-border searching have differentiated effects on iterative innovation and disruptive innovation of enterprises, which can help organizations quickly identify and repeatedly combine the specific knowledge elements required for innovation from massive knowledge sources in the digital context [19]. In addition, by establishing a complex system dynamics model and conducting the simulation analysis that knowledge cross-border searching influences enterprises' dual innovation in digital background, we clarify the role of digital resources such as big data and the Internet of Things in the context of digital transformation to successfully realize iterative innovation and disruptive innovation strategies. Our study has enriched the content and methods of the cross-study of knowledge management and innovation management to a certain extent $[9,20]$.

This study provides implications for enterprises to carry out knowledge searching strategy under the background of digital transformation. Firstly, when companies aim to improve iterative innovation capabilities, they should extensively search for and combine domain knowledge from ecology partners to enrich knowledge stock. For example, Xiaomi and Tencent solicit customer opinions and ideas to improve their products and adopt the innovative modes of "imitating one generation, developing one, and preresearching one generation" to achieve great success.

Secondly, when organizations focus on promoting disruptive innovation capabilities to effectively respond to the dynastic change of market needs, they should pay attention to searching for architectural knowledge that can effectively solve practical problems and communication strategies. For example, the success of Huawei's 5G technology is driven by the culture that always encourages employees to learn and innovate ideas or ways independently to develop disruptive technologies.

Thirdly, enterprises should strengthen the effective application of digital resources such as big data, Internet of Things, and cloud computing. According to IDC, the total amount of global data will increase from 33ZB in 2018 to $175 Z B$ in 2025. Thus, the business management environment is undergoing tremendous changes. In the process of organizing and combining external heterogeneous knowledge elements, companies can use digital resources to achieve innovation strategies and value-added of innovation results to improve the efficiency and effectiveness of resource utilization.

\section{Data Availability}

The data used to support the findings of this study are included within the article.

\section{Conflicts of Interest}

The authors declare that they have no conflicts of interest.

\section{Acknowledgments}

This work was supported by the Youth Project of Guangdong Provincial Philosophy and Social Science Plan (Grant Number: GD20YGL06), and the Youth Project of Regional Joint Fund Project of Guangdong Provincial Basic and Applied Basic Research Fund (Grant Number: 2020A1515110775). 


\section{References}

[1] P. Shapira, J. Youtie, K. Yogeesvaran, and Z. Jaafar, "Knowledge economy measurement: methods, results and insights from the Malaysian knowledge content study," Research Policy, vol. 35, no. 10, pp. 1522-1537, 2006.

[2] D. Ehls, S. Polier, and C. Herstatt, "Reviewing the field of external knowledge search for innovation: theoretical underpinnings and future (Re-)search directions," Journal of Product Innovation Management, vol. 37, no. 5, pp. 405-430, 2020.

[3] X. Shi, Z. Zheng, Q. Zhang, and H. Liang, "External knowledge search and firms' incremental innovation capability: the joint moderating effect of technological proximity and network embeddedness," Management Decision, vol. 58, no. 9, pp. 2049-2072, 2020.

[4] R. M. Grant, "Toward a knowledge-based theory of the firm," Strategic Management Journal, vol. 17, no. S2, pp. 109-122, 1996.

[5] G. Elia, A. Margherita, and G. Passiante, "Digital entrepreneurship ecosystem: how digital technologies and collective intelligence are reshaping the entrepreneurial process," Technological Forecasting \& Social Change, vol. 150, pp. 1-12, 2020.

[6] L. Rosenkopf and A. Nerkar, "Beyond local search: boundaryspanning, exploration, and impact in the optical disk industry," Strategic Management Journal, vol. 22, no. 4, pp. 287-306, 2001.

[7] R. Katila and G. Ahuja, "Something old, something new: a longitudinal study of search behavior and new product introduction," Academy of Management Journal, vol. 45, no. 6, pp. 1183-1194, 2002.

[8] J. Sterman, Business Dynamics: Systems Thinking and Modeling for a Complex World, Irwin/McGraw-Hill, NY, USA, 2000.

[9] S. Yayavaram, M. K. Srivastava, and M. Sarkar, "Role of search for domain knowledge and architectural knowledge in alliance partner selection," Strategic Management Journal, vol. 39, no. 8, pp. 2277-2302, 2018.

[10] M. Z. Ngoasong, "Digital entrepreneurship in a resourcescarce context," Journal of Small Business and Enterprise Development, vol. 25, no. 3, pp. 483-500, 2018.

[11] M. Chi, W. Wang, X. Lu, and H. Li, "Research on the relationship between digital business strategy profile and organizational restructuring ability: is it restrained or promoted?" Journal of Management Engineering, vol. 34, no. 4, pp. 11-20, 2020, in Chinese.

[12] W. Zhou and J. Sun, "Construction of digital dynamic capability of entrepreneurial incubation platform," Studies in Science of Science, vol. 38, no. 11, pp. 2040-2047+2067, 2020, in Chinese.

[13] M. Tripsas and G. Gavetti, "Capabilities, cognition, and inertia: evidence from digital imaging," Strategic Management Journal, vol. 21, no. 10-11, pp. 1147-1161, 2000.

[14] C. Wang, S. Rodan, M. Fruin, and X. Xu, "Knowledge networks, collaboration networks, and exploratory innovation," Academy of Management Journal, vol. 57, no. 2, pp. 484-514, 2014.

[15] C. C. J. M. Millar, O. Groth, and J. F. Mahon, "Management innovation in a VUCA world: challenges and recommendations," California Management Review, vol. 61, no. 1, pp. 5-14, 2018.
[16] M. S. Gary, M. Kunc, J. D. W. Morecroft, and S. F. Rockart, "System dynamics and strategy," System Dynamics Review, vol. 24, no. 4, pp. 407-429, 2008.

[17] J. P. Torres, M. Kunc, and F. O'brien, "Supporting strategy using system dynamics," European Journal of Operational Research, vol. 260, no. 3, pp. 1081-1094, 2017.

[18] S. A. Zahra and G. George, "Absorptive capacity: a review, reconceptualization, and extension," Academy of Management Review, vol. 27, no. 2, pp. 185-203, 2002.

[19] J. Wang and J. Lai, "Exploring innovation diffusion of twosided mobile payment platforms: a system dynamics approach," Technological Forecasting \& Social Change, vol. 157, pp. 1-17, 2020.

[20] C. Yu, C. Lin, Z. Zhang, and B. Ye, "Specialized knowledge search, management innovation and corporate performance: the moderating effect of cognitive evaluation," Management World, vol. 1, pp. 146-166, 2020, in Chinese. 